First publ. in: Cognition \& Emotion 21 (2007), 8, pp. 1721-1744

\title{
Event-related potentials to schematic faces in social phobia
}

\author{
Iris-Tatjana Kolassa, Stephan Kolassa, Frauke Musial, and \\ Wolfgang H. R. Miltner \\ Friedrich Schiller University of Jena, Jena, Germany
}

\begin{abstract}
Social phobia has been associated with an attentional bias for angry faces. This study aimed at further characterising this attentional bias by investigating reaction times, heart rates, and ERPs while social phobics, spider phobics, and controls identified either the colour or the emotional quality of angry, happy, or neutral schematic faces. The emotional expression of angry faces did not interfere with the processing of their colour in social phobics, and heart rate, N170 amplitude and parietal late positive potentials (LPPs) of these subjects were also no different from those of non phobic subjects. However, social phobics showed generally larger P1 amplitudes than non phobic controls with spider phobic subjects in between. No general threat advantage for angry faces was found. All groups identified neutral schematic faces faster and showed larger late positive amplitudes to neutral than to emotional faces. Furthermore, in all groups the N170 was modulated by the emotional quality of faces. This effect was most pronounced in the emotion identification task.
\end{abstract}

With a life-time prevalence rate of about 13\% (see Furmark, 2002; Westenberg, \& Liebowitz, 2004, for reviews), social phobia is one of the most frequent phobic disorders. Individuals with social phobia fear embarrassment, humiliation, or negative evaluation in social interaction and performance situations. Approval or disapproval is most directly signalled by facial expressions. For example, during dyadic interaction the display of anger in the face of one of the interaction partners is a common

Correspondence should be addressed to: Iris Tatjana

Department of Psychology, Clinical \& Neuropsychology, PO Box 5560, D25, University of Konstanz, D 78457 Konstanz, Germany. E mail: Iris.Kolassa@uni konstanz.de

This study was funded by grant Mi265/6 1 of the German Research Foundation (Deutsche Forschungsgemeinschaft) awarded to WHRM. We would also like to thank the German National Academic Foundation (Studienstiftung des deutschen Volkes) for awarding a doctoral grant to ITK.

Thanks are also due to Sandra Riske, Alexander Mohr, and Katharina Stoßel for their assistance in conducting the study. 
signal for the opposite that he/she has violated social rules or social expectations (compare Averill, 1982).

Cognitive models of anxiety (e.g., Eysenck, 1997; Rapee \& Heimberg, 1997; Williams, Mark, Watts, MacLeod, \& Mathews, 1997) have suggested that anxious subjects selectively attend to threat cues: individuals with social phobia carefully monitor the facial expressions of others for signs of negative evaluation, disapproval, or rejection, and rapidly detect such faces in the social environment of subjects (attentional bias). Furthermore, social phobics have difficulty in disengaging attention from such faces (Rapee \& Heimberg, 1997).

A common paradigm for the study of attentional biases in anxiety disorders is the emotional Stroop paradigm (MacLeod, 1991; Wells \& Matthews, 1994; Williams, Mathews, \& MacLeod, 1996). In this paradigm, the colour of words or pictures varying in personal emotional significance has to be identified either verbally or by pushing a button. The phenomenon that threatening stimulus attributes impair the processing of non-threatening stimulus characteristics has been called emotional interference. The difference in colournaming latencies between fear-related and neutral stimuli-the emotional Stroop effect - provides a measure of the attentional bias. Several studies reported emotional Stroop interference in patients with social phobia when colour-naming social threat words (Becker, Rinck, Margraf, \& Roth, 2001; Hope, Rapee, Heimberg, \& Dombeck, 1990; Lundh \& Öst, 1996; Maidenberg, Chen, Craske, Bohn, \& Bystritsky, 1996; Mattia, Heimberg, \& Hope, 1993; Spector, Pecknold, \& Libman, 2003).

Since detecting threatening faces and responding appropriately to them in terms of either attacking the conspecific or presenting signals and actions of submissiveness was critical for survival during evolution, several authors have suggested that angry faces may represent phylogenetic, generic signals of threat. Therefore, threatening faces may be fear-relevant not only for individuals with social phobia but for all humans (Öhman, 1986, 1993). According to this suggestion, threatening faces should be detected more rapidly and more efficiently than neutral stimuli or stimuli whose threatening qualities are of ontological origin (Öhman, Lundqvist, \& Esteves, 2001). In support of this theory, generalised social phobics and non-anxious controls both detected angry faces faster than happy ones in a neutral crowd in a face-in-the-crowd paradigm; however, the generalised social phobics showed even faster reactions to angry faces than the controls (GilboaSchechtman, Foa, \& Amir, 1999).

Recent studies by Öhman and co-workers have further shown that threat can also be induced by schematic faces depicting prototypical features of threat (Lundqvist, Esteves, \& Öhman, 1999, 2004; Esteves, \& Öhman, 2004). Using a visual search paradigm with schematic faces, Öhman et al. (2001) demonstrated faster and more accurate detection of threatening than friendly target faces. Similar results were obtained in a series of experiments 
with schematic faces by Fox, Lester, Russo, Bowles, Pichler, and Dutton (2000): subjects were faster in detecting a discrepant angry face in a neutral crowd than a happy face in a neutral crowd. Furthermore, when the eyebrows were removed from the face, which resulted in ambiguous faces, which could be interpreted as either sad or angry, a similar advantage for angry/sad faces was observed. Finally, response latencies for angry/sad target faces were less affected by the number of distractors in a display than response latencies for happy target faces, suggesting a highly efficient search for angry/sad faces but no "pop-out" effect.

From electrophysiological studies on brain responses to facial expressions, one would expect that fear-relevant angry faces induce larger amplitudes of early visual event-related potentials (ERPs) such as the occipital P1 and the posterior occipito-temporal N170 in general and even larger amplitudes of these potentials in social phobics. The P1 is known to be attention-sensitive (see Mangun, 1995; Luck, Woodman, \& Vogel, 2000, for a reviews), and modulated by personal affective judgement of faces as liked or disliked (Pizzagalli, Regard, \& Lehmann, 1999). The N170 is known to be a face-specific ERP component, elicited by human faces but not by animal faces, human hands, cars, or furniture (Bentin, Allison, Puce, Perez, \& McCarthy, 1996). Source localisation studies implicated the N170 to originate from posterior lateral temporal areas, possibly in the inferior temporal gyrus (Schweinberger, Pickering, Jentzsch, Burton, \& Kaufmann, 2002; compare also Henson et al., 2003). The N170 has been linked to late stages of structural encoding in which representations of global face configurations are generated for subsequent face-recognition processes (Eimer, 2000). Whereas some studies reported an emotional modulation of the N170 (Caharel, Courtay, Bernard, Lalonde, \& Rebaï, 2005; Kolassa \& Miltner, 2006; Pizzagalli, Lehmann, Koening, Regard, \& Pascual-Marqui, 2000), other studies did not find such an effect (Eimer \& Holmes, 2002; Eimer, Holmes, \& McGlone, 2003; Holmes, Vuilleumier, \& Eimer, 2003; Schupp et al., 2000). However, in the latter studies, facial emotion was either not task-relevant (Eimer et al., 2003; Holmes et al., 2003; Schupp et al., 2000) or the facial expression was presented outside of focal vision with subjects instructed to fixate on a cross in the centre of a screen while one facial picture was presented simultaneously at each outer area of the left and right area of the screen (Eimer \& Holmes, 2002). Thus, task differences might account for these different findings. This interpretation is corroborated by the findings of Kolassa and Miltner (2006), who observed a more pronounced emotional modulation of the N170 when subjects' task was to identify the emotion of a facial expression rather than the depicted person's gender.

In addition to early ERPs, studies exploring the processing of affective stimuli repeatedly showed larger parietal late positive potentials (LPPs) 
when subjects were processing emotionally arousing (pleasant and unpleasant) stimuli as compared to neutral ones (Cuthbert, Schupp, Bradley, Birbaumer, \& Lang, 2000; Keil et al., 2002; Schupp et al., 2000; Schupp, Junghöfer, Weike, \& Hamm, 2003, 2004a; see also Straube \& Miltner, 2006). Thus, if angry faces are more arousing and unpleasant for individuals with social phobia than for healthy controls, this should be reflected in enlarged LPPs in response to angry faces.

Furthermore, distinct heart rate response patterns to affective stimuli of varying intensity have been observed: In general, the heart rate decelerates as stimuli become more arousing or aversive (e.g., see Lang, Bradley, \& Cuthbert, 1997), resembling the "fear bradycardia" widely observed in animals (Campbell, Wood, \& McBride, 1997). Codispoti, Bradley, and Lang (2001) found a strong influence of emotionality on the orienting response, with neutral pictures eliciting the weakest and unpleasant pictures the strongest response, with pleasant pictures in between. With a further increment in threat, the response changes from orienting to defence, and the heart rate increases after a temporary cardiac deceleration (e.g., Graham, 1979; Sokolov, 1966). Studies on individuals with specific phobia found clear evidence for accelerated heart rates when phobic individuals viewed pictures of their feared object (e.g., Fredrikson, 1981; Globisch, Hamm, Esteves, \& Öhman, 1999; Hare \& Blevings, 1975). However, so far no study has investigated heart rate reactions to angry faces in social phobia.

This study investigated the attentional bias for angry faces in individuals with social phobia by measuring reaction times, heart rates, and eventrelated potentials in response to schematic emotional faces under two task conditions: an emotional Stroop paradigm and an emotion identification task. In the emotional Stroop task, subjects identified the colour of red- or blue-coloured angry, happy, or neutral faces, whereas in the emotion identification task subjects identified the emotional expressions of faces. Participants were individuals with social phobia, individuals with spider phobia as a clinical control group, and healthy control subjects. We expected emotional Stroop interference, i.e., prolonged response latencies when social phobic subjects were requested to identify the colour of angry faces compared to happy or neutral faces. Furthermore, we hypothesised finding a faster identification of angry faces than happy or neutral ones in all groups, with an even faster identification of angry faces by social phobic participants. Regarding ERPs and heart rates, enhanced decelerative responses, larger N170 amplitude, and larger late parietal positive potentials (LPPs) were expected in social phobics when processing angry schematic faces as compared to non-phobic control subjects. 


\section{METHODS}

\section{Pilot study}

Fifty-five subjects (mean age 23 years, $S D=3.28$, age range 19-32 years) rated the stimuli used in this study as to their affective valence and arousal with the Self-Assessment Manikin Scale (SAM; Lang, 1980). Of these participants, there were 18 individuals with social phobia ( 9 male, 9 female), 18 individuals with spider phobia (7 male, 11 female), and 19 control subjects (10 male, 9 female). See Table 1 for valence and arousal ratings.

Valence ratings varied by facial emotion, $F(2,104)=135.85, p=.0005$, $\varepsilon=.87$. All groups rated angry faces as most unpleasant, followed by neutral faces, while happy faces received the most pleasant ratings, all $p \mathrm{~s}<.0005$. Valence ratings did not differ between groups, $F(2,52)=2.65, p=.08$, although there was a slight tendency of social phobic individuals to rate all faces, and in particular angry faces, as more unpleasant than controls.

Arousal ratings also varied with the emotion of the depicted face, $F(2,104)=56.0, p=.0005, \varepsilon=.75$. All groups rated angry faces as more arousing than happy and neutral faces, both $p \mathrm{~s}<.0005$. Group affected arousal ratings, $F(2,52)=3.41, p=.04$. Social phobic subjects showed generally elevated arousal ratings compared to controls, $p=.01$, but not compared to spider phobics. Groups marginally differed in their arousal ratings of the different emotions as indicated by a barely significant interaction of group $\times$ emotion, $F(4,104)=2.65, p=.055, \varepsilon=.75$. LSD tests revealed higher arousal ratings for angry faces in individuals with social phobia compared to controls, $p=.005$, but not compared to spider phobics.

TABLE 1

Mean valence and arousal ratings $(M)$ and standard deviations $(S D)$ for schematic angry, happy, and neutral faces for each group

\begin{tabular}{lccc}
\hline Rating & Controls: $M(S D)$ & Social phobics: $M(S D)$ & Spider phobics: $M(S D)$ \\
\hline Valence & & & \\
Angry & $4.21(1.23)$ & $3.17(0.86)$ & $3.78(0.94)$ \\
Happy & $6.74(1.24)$ & $6.23(1.22)$ & $6.89(1.49)$ \\
Neutral & $5.50(1.13)$ & $5.31(0.81)$ & $5.56(1.04)$ \\
Arousal & & & \\
Angry & $4.05(1.75)$ & $5.83(2.04)$ & $5.28(1.74)$ \\
Happy & $2.95(1.18)$ & $3.50(1.50)$ & $2.72(1.36)$ \\
Neutral & $2.84(1.30)$ & $3.75(1.54)$ & $3.42(1.15)$ \\
\hline
\end{tabular}

Note. The SAM scale (Lang, 1980; Bradley \& Lang, 1994) ranges from 1 to 9 with $1=$ "highly unpleasant/low arousing" and 9="highly pleasant/highly arousing". 


\section{Subjects}

Fifty-six subjects (mean age 23.2 years, $S D=3.46$, age range 19-32 years) participated in the study: 19 social phobics (10 male, 9 female), 18 spider phobics (9 male, 9 female), and 19 normal controls (10 male, 9 female). Forty-four of the subjects also participated in the pilot study (13 controls, 17 social phobic individuals, 14 spider phobic individuals). Fifty-three participants were right-handed and three left-handed as measured by the Edinburgh handedness questionnaire (Oldfield, 1971).

Subjects were recruited by newspaper advertisement and announcements on campus bulletin boards. All participants provided informed consent and the procedures were approved by the ethics committee of the University of Jena. Participants were paid 6 euros per hour for participation. In addition, individuals with social phobia were offered a 10 -session group training of social skills (Hinsch \& Pfingsten, 2002), and spider-phobic subjects were offered a one-day spider phobia therapy (Öst, 1989).

Participants were screened with the Structured Clinical Interview for DSM-IV (SKID; Wittchen, Wunderlich, Gruschwitz, \& Zaudig, 1997). Controls were accepted for participation if they had no current or life-time diagnosis of any major disorders according to DSM-IV (American Psychiatric Association, 1994). Individuals with spider phobia and social phobia were included if they fulfilled DSM-IV criteria for spider phobia or social phobia, respectively. Fears of social phobics centred on situations related to speaking in front of others, talking with strangers and authority persons as well as performance situations. Participants completed German versions of the Social Phobia and Anxiety Inventory (SPAI; Fydrich, 2002; Turner, Beidel, Dancu, \& Stanley, 1989), the Beck Depression Inventory (BDI; Hautzinger, Bailer, Worall, \& Keller, 1995), the State-Trait Anxiety Inventory (STAI; Laux, Glanzmann, Schaffner, \& Spielberger, 1981), and the Spider Questionnaire (SPQ; Klorman, Weerts, Hastings, Melamed, \& Lang, 1974). See Table 2 for questionnaire values.

It is well known that depression and social phobia are highly comorbid (Merikangas et al., 1996; Schneier, Johnson, Hornig, Liebowitz, \& Weissman, 1992; Stein et al., 2001). Although individuals with social phobia scored on average higher on the BDI than the control groups, their scores were not in the range of a clinically significant depression, $M=9.42$, $S D=7.09$.

\section{Paradigm}

Schematic faces depicting angry, happy, and neutral facial expressions were used in this study (see Figure 1). The stimuli varied with respect to the angle of the eyebrows, the curvature of the mouth as well as the shape of the eyes. 
TABLE 2

Mean questionnaire values $(M)$ and standard deviations $(S D)$ for each group

\begin{tabular}{lcccl}
\hline Questionnaire & $\begin{array}{c}\text { Control group: } \\
M(S D)\end{array}$ & $\begin{array}{c}\text { Spider phobics: } \\
M(S D)\end{array}$ & $\begin{array}{c}\text { Social phobics: } \\
M(S D)\end{array}$ & \multicolumn{1}{c}{ One way ANOVA } \\
\hline SPQ & $2.47(1.78)$ & $20.61(2.66)$ & $2.58(1.95)$ & $F(2,53)=430.97, p<.001^{* *}$ \\
SPAI & $33.53(16.89)$ & $44.41(15.51)$ & $126.81(18.17)$ & $F(2,53)=171.72, p<.001^{\dagger *}$ \\
BDI & $2.68(2.71)$ & $4.94(4.76)$ & $9.42(7.09)$ & $F(2,53)=8.52, p=.001^{\dagger *}$ \\
STAI T & $30.79(5.92)$ & $33.50(8.05)$ & $50.47(6.61)$ & $F(2,53)=45.27, p<.001^{* *}$ \\
\hline
\end{tabular}

Notes: The German scores of the Social Phobia and Anxiety Inventory (SPAI) were transformed into the original scores (Turner et al., 1989). STAI-T, State-Trait Anxiety Inventory Trait Version; BDI, Beck Depression Inventory; SPQ, Spider Questionnaire.

${ }^{*}$ Control group is different than spider phobics $(p<.005)$. ${ }^{\dagger}$ Control group is different than social phobics $(p<.05)$. Spider phobics are different than social phobics $(p<.05)$.

The experiment consisted of two blocks of 90 trials each, with a short break between the blocks. In each block, 30 angry, 30 neutral, and 30 happy faces were shown, in each case 15 drawn with red and 15 with blue lines on a white background. Stimuli were shown for 1 second with a variable interstimulus interval of 2-3 s. Subjects' task was to identify in the first block the colour of the presented face as quickly and as accurately as possible (modified Stroop task), or in the second block the emotion of the depicted face (emotion identification task). Subjects indicated their response by pressing buttons on a button box with the index finger of their dominant hand. In order to be able to respond without looking at the button box, subjects performed a practice task before starting each block.

The presentation order of the two blocks as well as the assignment of buttons was counterbalanced across subjects. The order of the stimuli in each block was pseudorandomised: the same colour was only allowed up to four times in a row, the same facial expression with identical colour up to
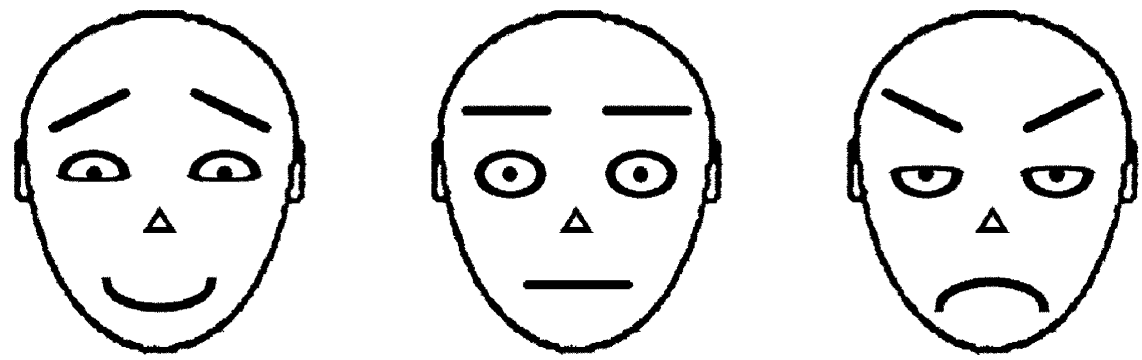

Figure 1. Schematic stimuli of happy, neutral, and angry faces. In the actual experiment, stimuli were coloured red or blue. 
three times in a row, and the same facial expression with different colours up to four times in a row.

\section{Assessment and analysis of EEG}

During the testing session, subjects sat in a comfortable chair in a soundattenuated room. Stimuli were presented on a 20-inch Sony monitor (resolution $800 \times 600$ ) with the software ERTS (Experimental Runtime System, Version 3.18, BeriSoft, Germany). EEG was recorded with $62 \mathrm{Ag} /$ $\mathrm{AgCl}$-electrodes mounted in an Easy-Cap (Falk Minow Services, Germany) according to the international 10-10 system (Chatrian, Lettici, \& Nelson, 1998) with additional non-standard electrodes (AF1, AF2, PO1, PO3) at frontal and occipital sites spaced equally between the standard electrodes. $\mathrm{Cz}$ served as a reference electrode, and a ground electrode was placed on the forehead. Impedances of all electrodes were kept below $5 \mathrm{k} \Omega$. Vertical and horizontal electro-oculograms (VEOG and HEOG) were measured for off-line correction of eye movements and blink artefacts. Synamps amplifiers were used for EEG and EOG acquisition. All signals were continuously sampled in AC-mode at a rate of $500 \mathrm{~Hz}$ (gain $=1000$, low pass filter $=70 \mathrm{~Hz}$, high pass filter $=0.05 \mathrm{~Hz}$ ). Data acquisition was performed with NEUROSCAN software (Acquire 4.1-1, Neurosoft, 1999).

The EEG raw data were filtered (low pass $=30 \mathrm{~Hz}, 24 \mathrm{~dB} /$ oct, high pass $=0.1 \mathrm{~Hz}, 24 \mathrm{~dB} / \mathrm{oct}, 50 \mathrm{~Hz}$ Notch$)$, segmented (200 ms pre- to $1300 \mathrm{~ms}$ post-stimulus), corrected for blinks and eye movements (Gratton, Coles, \& Donchin, 1983), and screened for artefacts using the software Brain Vision Analyser 1.04 (Brain Products $\mathrm{GmbH}$, Germany). Trials containing artefacts (amplitude deviations of $\pm 150 \mu \mathrm{V}$ ) were rejected. Artefact-free EEG epochs were averaged for each subject, condition, and electrode. All epochs were aligned to the $200 \mathrm{~ms}$ pre-stimulus baseline and were rereferenced to an average reference. The data of 3 subjects ( 2 male controls, 1 male social phobic) had to be excluded because of severe occipito-parietal alpha activity. The data of 2 additional subjects (1 male control, 1 male social phobic) had to be excluded because no component structure for early components (P1, N170) was visible. N170 peaks were detected on leads P7 and P8 (100-200 ms), and P1 amplitudes were detected on electrodes $\mathrm{O} 1$ and O2 (50-100 ms). Two parietal late positive components were observed in the time windows $320-360$ and $450-550 \mathrm{~ms}$, which is consistent with previous studies that found multiple late positive components in response to emotional stimuli (e.g., Johnston, Miller, \& Burleson, 1986; Kolassa, Musial, Mohr, Trippe, \& Miltner, 2005; Kolassa, Musial, Kolassa, \& Miltner, 2006; Mini, Palomba, Angrilli, \& Bravi, 1996). Since these positivities were rather extended over long time epochs without a clear peak structure, mean amplitudes were analysed within the time intervals $320-360 \mathrm{~ms}$ (P300) and 
450-550 ms (late positive potential, LPP) on electrodes P3, Pz, and P4. The analysis of mean amplitudes is more conservative and reliable than the detection of peaks.

\section{Assessment and analysis of heart rate data}

The electrocardiogram (ECG) was measured according to Wilson et al. (1944) using DASYLab 5.0 (Datalog GmbH, Germany): two precordial leads (Ag/AgCl-electrodes) were placed at V3 and $\mathrm{V} 4$, a reference electrode (V3R) was placed at the corresponding right side of $\mathrm{V} 3$, and a fourth ground electrode was attached to the right waist. To improve impedances, electrode sites were cleaned with alcohol. The ECG was amplified with a gain of $0.5 \mathrm{mV} / \mathrm{V}$, high-pass filtered at $0.53 \mathrm{~Hz}$, and lowpass filtered at $30 \mathrm{~Hz}$. Respiration was measured by an elastic belt containing a piezoelectrical element, placed at the abdomen (male) or the chest (female). Respiration data were amplified with a gain of $5 \mathrm{mV} / \mathrm{V}$, highpass filtered at $10 \mathrm{~Hz}$, and low-pass filtered at $1 \mathrm{~Hz}$.

Heart rates were analysed with Brain Vision Analyser 1.04. By visual inspection of the data it was assured that respiration was not stimuluslocked. In this case, the influence of respiration on heart rate (respiratory sinus arrhythmia) was reduced by averaging. Heart rates were determined by $\mathrm{R}$-wave detection and subsequent conversion into beats per minute (bpm) in $500 \mathrm{~ms}$ intervals between $500 \mathrm{~ms}$ pre- and $3000 \mathrm{~ms}$ post-stimulus. Heart rate changes were computed by subtracting the $500 \mathrm{~ms}$ pre-stimulus baseline from the post-stimulus heart rates. Averaging these heart rates per time interval over stimuli is a well-established procedure (Graham, 1978).

\section{Statistical analysis}

For the analysis of response times, all trials were excluded in which no reaction occurred, the response was wrong, or the reaction time was below $200 \mathrm{~ms}$. A $3 \times 2 \times 3$ repeated-measures ANOVA was conducted with the between factor Group and the repeated-measures factors Task (colour vs. emotion identification) and Emotion (angry, happy, neutral).

For the analysis of heart rates, a $3 \times 2 \times 3 \times 6$ repeated-measures ANOVA was calculated with the between factor Group and the repeated-measures factors Task, Emotion, and Time (in intervals of $500 \mathrm{~ms}$ ). P300 and LPP amplitudes were analysed by a $3 \times 2 \times 3 \times 3$ ANOVA with the between factor Group and the repeated-measures factors Task (colour vs. emotion identification), Emotion (angry, happy, neutral), and Laterality (left, central, right). P100 and N170 amplitudes were analysed by ANOVAs with the between factor Group and the repeated-measures factors Task, Emotion, and Laterality (left, right). 
Greenhouse-Geisser $(\varepsilon)$ corrections for violations of sphericity were used when appropriate (Greenhouse \& Geisser, 1958). Significant effects in an ANOVA were further analysed by simple-effects ANOVAs and least significant difference (LSD) tests.

\section{RESULTS}

\section{Reaction times}

Groups did not differ with respect to response errors (omissions and incorrect choices), Kruskal-Wallis $\chi^{2}(2, N=56)=1.43, p=.49$. Overall, subjects failed to respond in $2.7 \%$ of trials, and incorrect responses were observed in $2.2 \%$ of trials.

Subjects identified the colour of a stimulus faster than the facial emotion, main effect of Task, ${ }^{1} F(1,53)=471.01, p=.0005$. Neutral faces were identified faster than emotional faces, main effect of Emotion, $F(2,106)=$ $6.45, p=.003, \varepsilon=.97$. Subsequent pairwise comparisons revealed faster identification of neutral than happy, $p=.002$, and of neutral than angry faces, $p=.008$. The influence of facial emotion on response latencies depended on the performed task, Task $\times$ Emotion, $F(2,106)=6.46$, $p=.002, \varepsilon=.97$. In the colour identification task, response latencies were very similar for the three different emotions, whereas in the emotion identification task, response latencies were faster for neutral than happy faces, $p=.001$, and neutral than angry faces, $p=.003$ (see Figure 2). No difference between social phobic individuals and the control groups were observed regarding response latencies. However, as can be seen in Figure 2, spider phobics seemed to respond generally faster than the other groups, which was confirmed by a specific contrast, $p=.02$.

\section{Heart rates}

Groups did not differ in baseline heart rates $(-500-0 \mathrm{~ms}), F(2,53)=0.31$, $p=.73$. Heart rates showed a decelerative response pattern, main effect of Time, $F(5,265)=43.64, p=.0005, \varepsilon=.32$ (see Figure 3). More pronounced decelerations were observed in the emotion than in the colour identification task, main effect of Task, $F(1,53)=9.91, p=.003$, and interaction of Time $\times$ Task, $F(5,265)=11.06, p=.0005, \varepsilon=.51$. The interactions Time $\times$ Emotion, $F(10,530)=2.43, p=.055, \varepsilon=.36$, and Time $\times$ Task $\times$ Emotion $\times$

\footnotetext{
${ }^{1}$ It should be kept in mind that the colour identification task may have been easier and less complex than the emotion identification task. Thus, any task effects in this and subsequent dependent variables may reflect response differences rather than processing differences between the tasks. However, comparing the two tasks is not the main focus of the present study.
} 

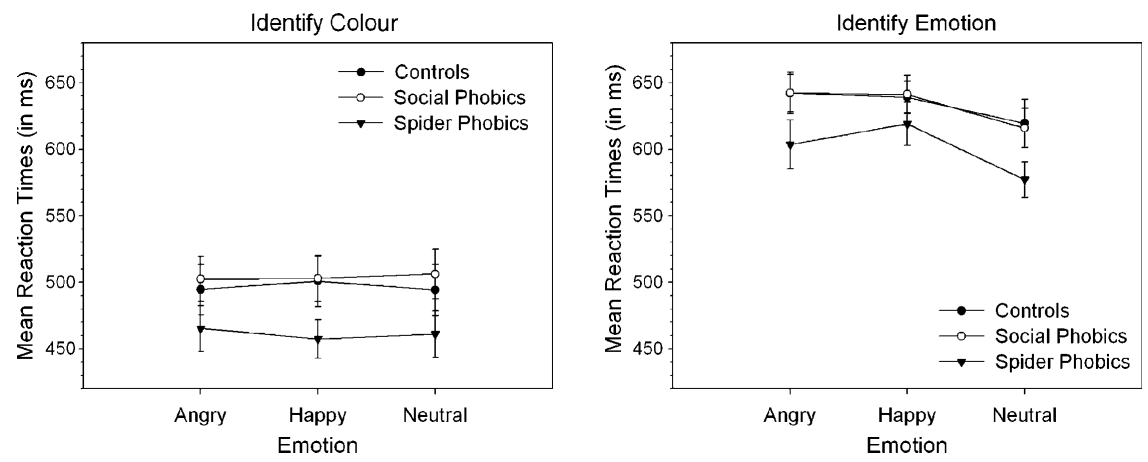

Figure 2. Mean response latencies and $S E$ for colour (left) and emotion (right) identification of angry, happy, and neutral faces for each group.

Group, $F(20,530)=1.91, p=.07, \varepsilon=.36$, failed significance. Thus, no significant influence of emotion or group was observed (compare Figure 3).

\section{Event related potentials}

Analysis of P1. Phobic subjects showed larger P1 amplitudes than controls, main effect of Group, $F(2,48)=4.64, p=.01$. Subsequent LSD tests showed that P1 amplitudes were larger in social phobic subjects than in controls, $p=.004$, whereas the difference between controls and spider phobic individuals failed significance, $p=.12$ (compare Figure 4).

Analysis of N170. N170 amplitude varied with facial emotion, main effect of Emotion, $F(2,96)=34.90, p=.0005, \varepsilon=.91$ (see Figure 5). Angry faces elicited the largest N170 amplitudes, followed by happy faces, and the smallest N170 amplitudes were observed for neutral faces (all $p \mathrm{~s}<.0005$ ). Furthermore, the effect of emotion on N170 amplitudes varied by task,
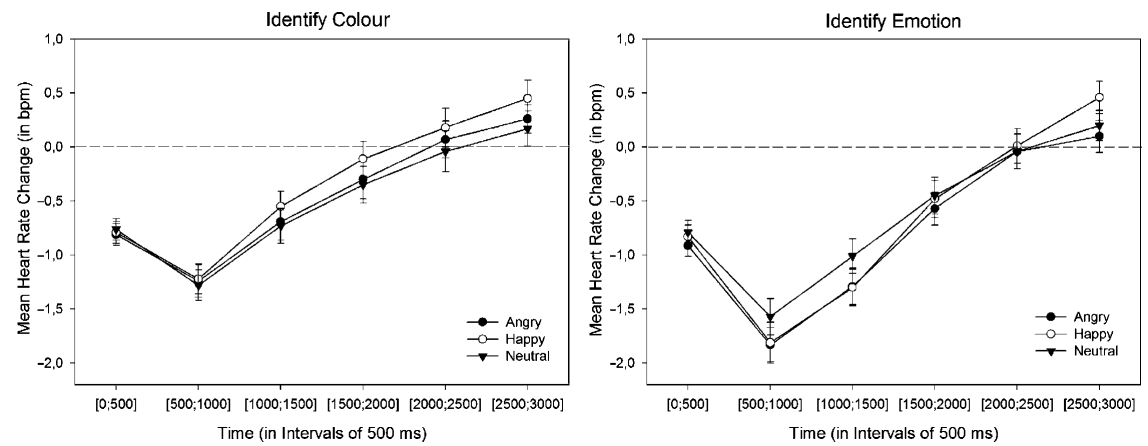

Figure 3. Mean heart rate changes (and $S E$ ) in beats per minute (bpm) in time intervals of $500 \mathrm{~ms}$ in response to angry, happy and neutral faces. 


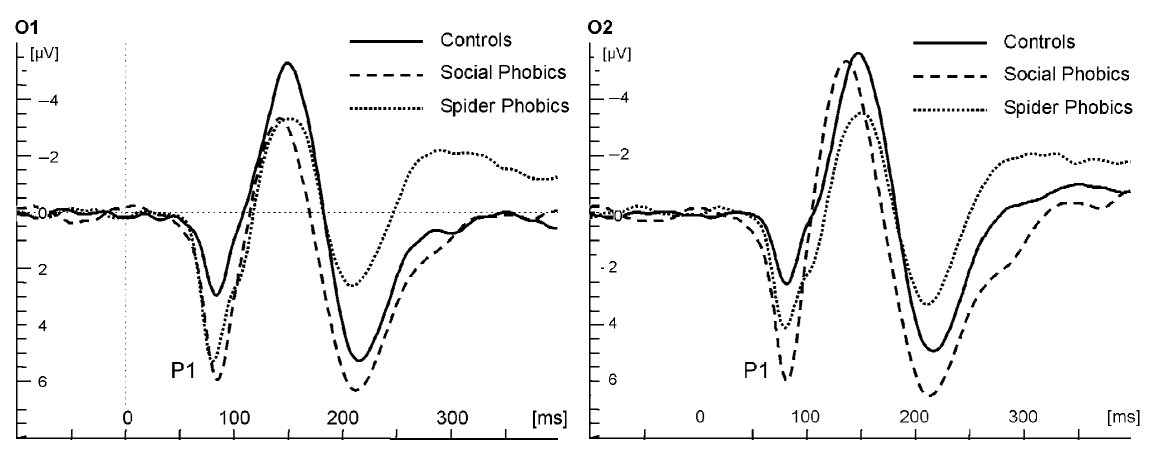

Figure 4. Grand average ERPs on electrode $\mathrm{O} 1$ (left) and $\mathrm{O} 2$ (right) for controls, social phobics and spider phobics.

Task $\times$ Emotion, $F(2,96)=5.82, p=.004, \varepsilon=.99$. Whereas in the colour identification task larger N170 amplitudes were observed for angry than neutral, $p=.0005$, and for happy than neutral faces, $p=.01$, but not for angry than happy faces, in the emotion identification task, N170 amplitudes
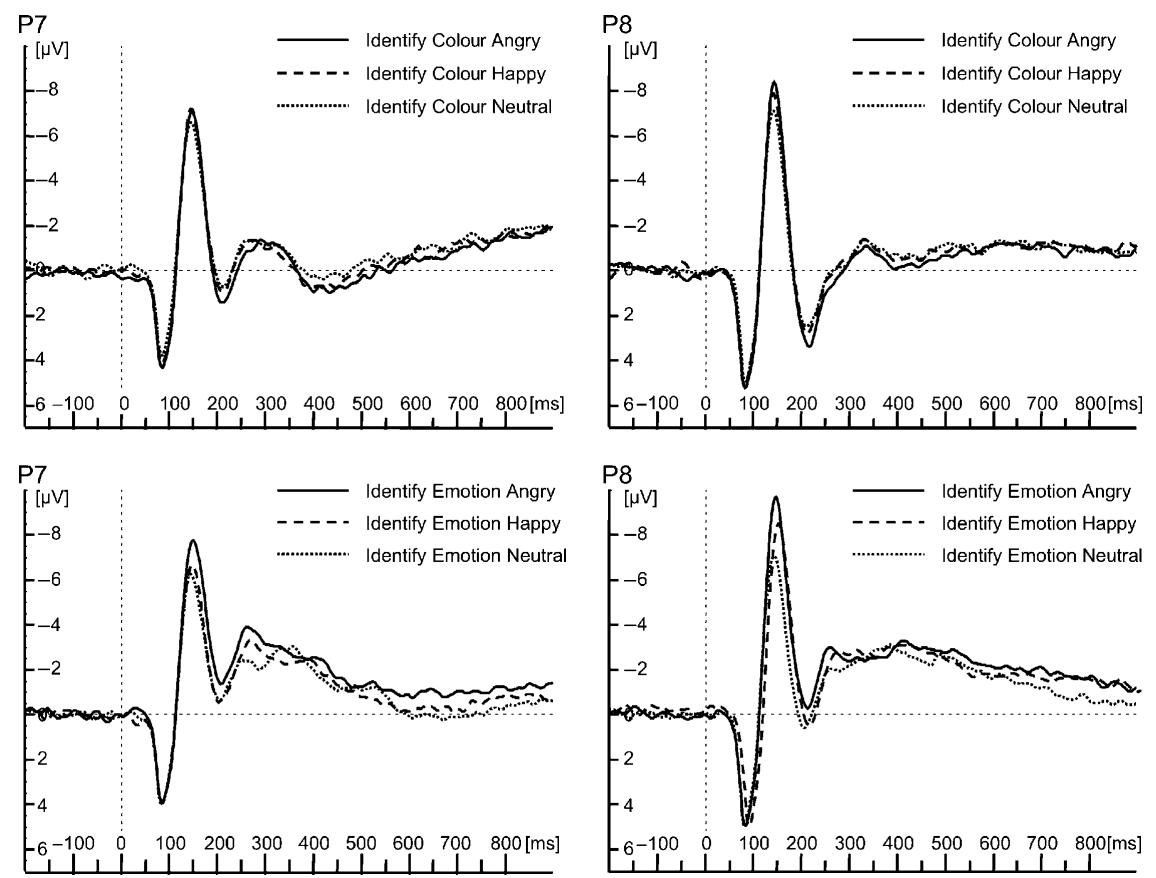

Figure 5. Grand average ERPs to angry, happy, and neutral faces in the colour (upper row) and emotion (lower row) identification task on electrode P7 (left) and P8 (right). 
were largest for angry faces, followed by happy, and then neutral faces (all $p s<.0005)$.

N170 amplitude were marginally larger on the right than on the left hemisphere, main effect of Laterality, $F(1,48)=3.29, p=.08$. However, this difference was only significant for angry faces, Laterality $\times$ Emotion, $F(2,96)=5.08, p=.01, \varepsilon=.89$.

Analysis of P3. Mean P3 amplitudes were larger for colour than emotion identification, main effect of Task, $F(1,48)=14.73, p=.0005$ (see Figure 6). Furthermore, P3 was largest over central electrode sites, main effect of Laterality, $F(2,96)=30.49, p=.0005, \varepsilon=.87$. Subsequent pairwise comparisons showed that amplitudes were larger over central than over left or right sites, both $p \mathrm{~s}=.0005$, with a larger right than left hemispheric positivity, $p=.007$. A significant interaction of Emotion $\times$ Laterality, $F(4,192)=2.77, p=.04, \varepsilon=.79$, was observed. P3 was larger for angry than for neutral faces over the left hemisphere, $p=.007$. Neither in the emotion nor in the colour identification task did individuals with social phobia show larger P3 amplitudes in response to angry faces.

Analysis of LPP. A larger positivity in the $450-550 \mathrm{~ms}$ range was observed for emotion than for colour identification, main effect of Task, $F(1,48)=52.35, p=.0005$. LPP was influenced by emotion, but only in the

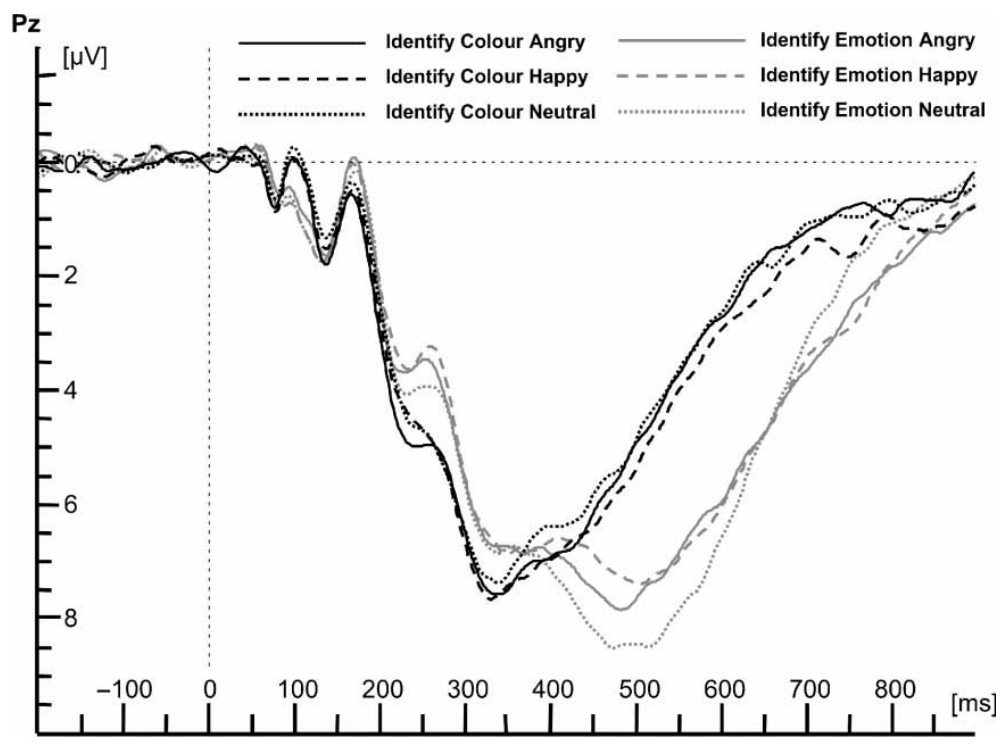

Figure 6. Grand average ERPs on electrode Pz in response to angry, happy, and neutral faces when identifying the colour or the emotion of the facial expression. 
emotion and not in the colour identification task, Task $\times$ Emotion, $F(2,96)=5.27, p=.007, \varepsilon=.98$ (compare Figure 6). All groups showed larger positivities for neutral than angry, $p=.01$, and for neutral than happy faces, $p=.003$. LPP was larger over central than right or left sites, main effect of Laterality, $F(2,96)=30.74, p=.0005, \varepsilon=.97$. This effect was more pronounced in the emotion than in the colour identification task, Task $\times$ Laterality, $F(2,96)=12.21, p=.0005, \varepsilon=.94$. Finally, a significant interaction of Emotion $\times$ Task $\times$ Laterality, $F(4,192)=2.69, p=.04, \varepsilon=.87$, but no significant influence of group was observed.

\section{DISCUSSION}

This study did not find evidence of abnormalities in the processing of schematic angry faces in individuals with social phobia: Results neither reveal an emotional Stroop interference in social phobic individuals when subjects were requested to identify the colour of angry schematic faces, nor a faster identification of angry schematic faces than the control groups. In addition, social phobic subjects did not show abnormalities in heart rates or ERPs when processing angry schematic faces. Yet, individuals with social phobia differed from the control group in that they rated all schematic faces, in particular angry faces, as more arousing than control subjects. Furthermore, social phobics showed generally larger P1 amplitudes than controls. However, P1 amplitudes of social phobics and spider phobics did not differ from one another, suggesting that large P1 amplitudes in response to emotional faces might represent a general pattern of phobic subjects processing emotional faces, rather than being only a peculiarity of social phobics.

A second important result of the study was that no evidence for a general threat advantage was observed. Schematic angry faces were not identified significantly faster than happy or neutral faces. Instead, neutral schematic faces were identified faster than emotional schematic face, which corresponded well with the larger LPP amplitudes to neutral than to emotional faces in the emotion identification task. Furthermore, all groups showed an emotional modulation of the N170, which was even more pronounced in the emotion than in the colour identification task: Angry faces elicited largest and neutral faces smallest N170 amplitudes, with happy faces in between.

\section{Behavioural data}

Absence of emotional Stroop interference. In contrast to previous studies using social threat words (Becker et al., 2001; Hope et al., 1990; Lundh \& Öst, 1996; Maidenberg et al., 1996; Mattia et al., 1993; Spector et al., 2003) the present study found no emotional Stroop interference in social phobic 
individuals when subjects were requested to colour-name angry faces. This finding is in accordance with a study by Kolassa and Miltner (2006), who also observed no emotional interference in a modified emotional Stroop paradigm where subjects had to identify the gender of angry faces in photographic images. Similarly, two recent studies with spider phobic subjects also found no Stroop interference when spider phobic subjects were asked to identify the colour of photographic (Kolassa et al., 2005) or schematic (Kolassa et al., 2006) pictures of their feared stimulus. As argued before (Kolassa \& Miltner, 2006), it is possible that pictures of angry faces are not specifically related to the concerns of social phobics, which is in line with the pilot study revealing only low specificity of angry faces for social phobic individuals versus other groups in valence and arousal ratings. In addition, pictures of angry faces - in contrast to social threat words - may not raise semantic associations to emotional concerns of social phobic patients (compare Mathews \& Klug, 1993), and thus do not cause interference. Alternatively, it is possible that identifying the colour can be accomplished by just taking a global view of the stimulus without having to focus on the specific features of the schematic face.

No threat advantage for angry faces. This study found neither a facilitated identification of angry facial expression in general, nor for social phobics in particular, as was originally hypothesised by studies reporting advantageous processing of negative faces or fear-relevant stimuli as compared to positive faces or neutral objects, respectively (e.g., Fox et al., 2000; Hansen \& Hansen, 1988; Öhman et al., 2001; Tipples, Atkinson, \& Young, 2002-which however comprised visual search tasks in contrast to the emotion identification task in the present study). However, we also did not find a happy face advantage, which was observed in a similar study using photographic face images (Kolassa \& Miltner, 2006), and was also reported by several other authors (Billings, Harrison, \& Alden 1993; Harrison, Gorelczenko, \& Cook, 1990; Hugdahl, Iversen, \& Jonsen, 1993; Kaufmann \& Schweinberger, 2004; Kirita \& Endo, 1995; Leppänen, Tenhunen, \& Hietanen, 2003; Schweinberger, Baird, Blümler, Kaufmann, \& Mohr, 2003; Stalans \& Wedding, 1985; Stanners, Byrd, \& Gabriel, 1985).

The faster identification of neutral faces in the emotion identification task observed in the present study was an unexpected finding and deserves an explanation. Three explanations are plausible. First, the neutral schematic face might have been easier to distinguish from the happy and angry schematic face because the emotional faces shared more similar properties in terms of diagonality of lines and shape of eyes compared to the neutral face. In particular, the neutral face's round eyes may have popped out, leading to a response time advantage. Second, the neutral face was less complex than the emotional faces: the eyebrows and the mouth of the neutral face are 
horizontal lines, while the emotional faces have angular lines for eyebrows, curved mouths, and half circles rather than ellipses for eyes. This has also been noted in a similar study by Öhman et al. (2001), who observed that the detection of a deviant target among neutral faces was faster than among emotional distractors. Third, it is possible that recognising the facial emotion of a schematic face takes longer and requires different, less automated, cognitive processes than identifying the emotion of a real face. For example, the identification of the emotion of a schematic face might be a more cognitive process of adding up single elementary features in order to deduce the depicted facial emotion from their configuration. In fact, participants may have identified the expression by focusing on single facial features such as eyebrows, mouth, or eyes, because every single one of these features already conveyed enough information to be able to classify the face's expression. Again, in this case, the neutral face may have been easier to identify than the emotional ones, since it consisted of more horizontally and less diagonally oriented lines and round eyes. In particular, eye widening observed in a conspecific is evidence of their increased vigilance, and a suggestion to the observer that they would do well to adopt a similar state (Whalen, 1998). If participants mainly focused on the eyes, the wide-eyed expression in neutral faces might have elicited an angry or fearful expression. In conclusion, it seems that the use of schematic as compared to real face pictures makes a difference in terms of study outcome, and thus should be considered in future studies.

Generally faster responses in spider phobic individuals. An interesting finding of the present study was that spider phobic individuals responded generally faster than both other groups, which is in accordance with a general hypervigilance in phobic patients (compare Eysenck, 1991, 1992, 1997). Lang, McTeague, and Cuthbert (in press) showed that individuals suffering from specific phobia are most reactive to specific cues in the environment, e.g., their startle reflex was most pronounced in a startle probe modulation task involving imagery of social and survival threat. However, defensive reflexes were diminished with increasing generalised anxiety and depression, which is assumed to increase along the anxiety disorder spectrum: specific phobia $\rightarrow$ social phobia $\rightarrow$ panic disorder with agoraphobia $\rightarrow$ generalised anxiety disorder (Brown, Campbell, Lehman, Grisham, \& Mancil, 2001; Cuthbert et al., 2003; Lang et al., in press), providing an explanation for the social phobic individuals' reacting slower than spider phobic persons. Lang et al. (in press) suggested that generalised anxiety and stronger depressive symptoms, as observed in the social phobic persons in the present study, additively attenuate startle potentiation to imagined threat in anxiety disordered patients. It has been shown that this reflex pattern is not specific to fear cues that are related to phobics' clinical 
problems (Cook, Melamed, Cuthbert, McNeil, \& Lang, 1988; Cuthbert et al., 2003).

\section{Heart rates}

In contrast to the results observed in individuals with specific phobia in response to feared stimuli (Fredrikson, 1981, Globisch et al., 1999; Hare \& Blevings, 1975; however see Flykt \& Caldara, 2006), this study did not find an accelerative reaction in social phobic persons in response to angry schematic faces. This finding is consistent with a recent study by Kolassa and Miltner (2006), who also did not observe accelerated heart rates in response to photographic angry faces in social phobic individuals. Similarly, Merckelbach, van Hout, van den Hout, \& Mersch, (1989) investigated the processing of angry and happy faces as well as neutral objects in social phobics and controls and did not find differences between social phobics and normals with respect to pleasantness ratings, skin conductance response or eyeblink rate. Furthermore, Vrana and Gross (2004) exposed high and low speech fearful persons to joyful, angry and neutral face photographs and found a deceleration in heart rates, which was larger for neutral and angry than for joyful expressions. Consistent with the present findings, highly speech fearful individuals did not show a heart rate acceleration in response to angry faces.

\section{Event related potentials}

Enhanced P1 amplitudes in social phobics. The P1 amplitude was not enlarged for angry faces in individuals with social phobia, but instead was generally larger in social phobics than in controls, with spider phobic subjects showing P1 amplitudes in between controls and social phobics. Since the P1 is thought to be attention-sensitive (see Mangun, 1995, for a review), the present data may be indicative of a hypervigilance in phobic subjects (Eysenck, 1991, 1992, 1997), which may have been increased in persons with social phobia by the performance situation posed by the experiment. Similar results were already reported by previous ERP (Kolassa et al., 2006) and fMRI studies (Straube, Mentzel, \& Miltner, 2005). In the latter study, social phobic individuals exhibited increased activation of extrastriate visual cortex regardless of facial expression, suggesting a state of alertness or hypervigilance in the visual cortex, which might possibly be triggered by re-entrant projections from the amygdala to the visual system that enhance attention and perceptual processing of motivationally relevant events (Amaral, Price, Pitkanen, \& Carmichael, 1992).

Emotional modulation of the N170. The emotional modulation of the N170 component is in agreement with other recent studies, which reported a 
modulation of the N170 by facial emotion (Caharel et al., 2005; Kolassa \& Miltner, 2006). As already discussed in Kolassa and Miltner (2006), the reason why some earlier studies did not find an emotional modulation of the N170 may lie in task differences. In the earlier studies (Eimer \& Holmes, 2002; Holmes et al., 2003; Schupp et al., 2004b), the detection of the facial emotion was not explicitly task relevant.

However, the current study raises several important questions. Emotional schematic faces led to larger N170 amplitudes than neutral schematic faces in the colour identification task. This effect was even more pronounced in the emotion identification task with angry schematic faces eliciting even larger N170 amplitudes than happy schematic faces. These findings are in conflict with findings by Kolassa and Miltner (2006), who reported larger N170 amplitudes for happy compared to angry faces or neutral faces when using photographic face images. Complicating things even more, Caharel et al. (2005) reported larger N170 amplitudes for emotional expressions of disgust than for neutral or smiling faces. Thus, although it has been repeatedly found that the N170 is modulated by facial emotion, it remains unclear which task or stimulus properties are responsible for the different results of the three studies.

Finally, the present study could not replicate deviations of the N170 when social phobics process emotional faces, as was found by Kolassa and Miltner (2006) with photographic face images. Whether this is due to the schematic face stimuli used remains to be investigated by future studies.

Emotional modulation of parietal late positive potentials (LPPS). The present study found no abnormalities in late parietal positive potentials in individuals with social phobia when processing angry schematic faces. This observation is consistent with an analogous study using photographic face images (Kolassa \& Miltner, 2006). In contrast, in a similar study with spider phobic individuals, spider fearful subjects showed enlarged LPPs in response to their feared stimulus (Kolassa et al., 2005). Thus, it seems that angry faces do not activate the fear network in individuals with social phobia in the same way as spiders do in spider phobic persons (compare Kolassa et al., 2005; Miltner et al., 2005).

In contrast to previous studies (e.g., Cuthbert et al., 2000; Keil et al., 2002; Schupp et al., 2000; Schupp et al., 2003; Schupp et al., 2004b), this study did not find larger LPPs for emotional compared to neutral schematic faces. Instead, larger LPP amplitudes for neutral than emotional schematic faces were observed. However, this finding is in agreement with the response-time pattern in the emotion identification task: neutral schematic faces were identified faster than emotional schematic faces. Since the emotional modulation of the LPP is a well-established finding, this is a strong argument that the neutral faces somehow popped out in this 
experimental design, possibly leading to an oddball effect. In particular, the round eyes appeared only in one third of the trials, whereas happy and angry faces shared more similar features. Furthermore, it is possible that our neutral faces - although rated in the valence and arousal ratings as low arousing and unpleasant, as one would expect - actually depict threatening faces, given their staring eyes and the closed mouth with tense lips.

In conclusion, this study allowed three valuable insights: First, it found no evidence of abnormalities in the processing of angry schematic faces in individuals with social phobia. Second, it found evidence for a cortical hypervigilance in social phobia, expressed as generally increased P1 amplitudes to emotional faces, regardless of facial expression. Third, the direct comparison of the nearly identical studies by Kolassa and Miltner (2006) using photographic faces and the present study using schematic faces suggests that schematic faces might lead to different behavioural and electrophysiological response patterns than real emotional face images. Thus, schematic faces appear to offer valuable insights on human face processing, but results from studies using schematic faces should be generalised to face processing in general only with care.

Manuscript received 22 December 2005 Revised manuscript received 15 January 2007

Manuscript accepted 16 January 2007

First published online 12 June 2007

\section{REFERENCES}

Amaral, D. G., Price, J. L., Pitkanen, A., \& Carmichael, S. T. (1992). Anatomical organization of the primate amygdaloid complex. In J. P. Aggleton (Ed.), The amygdala: Neurobiological aspects of emotion, memory, and mental dysfunction (pp. 1 66). New York: Wiley.

American Psychiatric Association. (1994). Diagnostic and statistical manual of mental disorders (4th ed.). Washington, DC: Author.

Averill, J. R. (1982). Anger and aggression: An essay on emotion. New York: Springer Verlag.

Becker, E. S., Rinck, M., Margraf, J., \& Roth, W. T. (2001). The emotional Stroop effect in anxiety disorders. General emotionality or disorder specificity. Anxiety Disorders, 15, 147 159.

Bentin, S., Allison, T., Puce, A., Perez, E., \& McCarthy, G. (1996). Electrophysiological studies of face perception in humans. Journal of Cognitive Neuroscience, 8, 551565.

Billings, L. S., Harrison, D. W., \& Alden, J. D. (1993). Age differences among women in the functional asymmetry for bias in facial affect perception. Bulletin of the Psychonomic Society, 31,317320 .

Brown, T. A., Campbell, L. A., Lehman, C. L., Grisham, J. R., \& Mancil, R. B. (2001). Current and lifetime comorbidity of the DSM IV anxiety and mood disorders in a large clinical sample. Journal of Abnormal Psychology, 110, 585599.

Caharel, S., Courtay, N., Bernard, C., Lalonde, R., \& Reba1, M. (2005). Familiarity and emotional expression influence an early stage of face processing: An electrophysiological study. Brain and Cognition, 59, 96100. 
Campbell, B. A., Wood, G., \& McBride, T. (1997). The origins of orienting and defensive responses: An evolutionary perspective. In P. J. Lang, R. F. Simons, \& M. Blaban (Eds.), Attention and orienting: Sensory and motivational processes (pp. 41 67). Hillsdale, NJ: Lawrence Erlbaum Associates, Inc.

Chatrian, G. E., Lettici, E., \& Nelson, P. L. (1998). Modified nomenclature for the $10 \%$ electrode system. Journal of Clinical Neurophysiology, 5, 183186.

Codispoti, M., Bradley, M. M., \& Lang, P. J. (2001). Affective reactions to briefly presented pictures. Psychophysiology, 38(3), 474478.

Cook, E. W., III, Melamed, B. G., Cuthbert, B. N., McNeil, D. W., \& Lang, P. J. (1988). Emotional imagery and the differential diagnosis of anxiety. Journal of Consulting and Clinical Psychology, 56, 734740.

Cuthbert, B. N., Lang, P. J., Strauss, C., Drobes, D., Patrick, C. J., \& Bradley, M. M. (2003). The psychophysiology of anxiety disorder: Fear memory imagery. Psychophysiology, 40, 407 422.

Cuthbert, B. N., Schupp, H. T., Bradley, M. M., Birbaumer, N., \& Lang, P. J. (2000). Brain potentials in affective picture processing: Covariation with autonomic arousal and affective report. Biological Psychology, 52, 95111.

Eimer, M. (2000). The face specific N170 component reflects late stages in the structural encoding of faces. NeuroReport, 11, 23192324.

Eimer, M., \& Holmes, A. (2002). An ERP study on the time course of emotional face processing. NeuroReport, 13, 15.

Eimer, M., Holmes, A., \& McGlone, F. P. (2003). The role of spatial attention in the processing of facial expression: An ERP study of rapid brain responses to six basic emotions. Cognitive, Affective, \& Behavioral Neuroscience, 3, 97110.

Eysenck, M. W. (1991). Cognitive factors in clinical psychology: Potential relevance to therapy. In M. Briley \& S. E. File (Eds.), New concepts in anxiety. London: Macmillan.

Eysenck, M. W. (1992). Anxiety: The cognitive perspective. Hillsdale, NJ: Lawrence Erlbaum Associates, Inc.

Eysenck, M. W. (1997). Anxiety and cognition: A unified theory. Hove, UK: Psychology Press.

Flykt, A., \& Caldara, R. (2006). Tracking fear in snake and spider fearful participants during visual search: A multi response domain study. Cognition and Emotion, 20, 10751091.

Fox, E., Lester, V., Russo, R., Bowles, R. J., Pichler, A., \& Dutton, K. (2000). Facial expressions of emotion: Are angry faces detected more efficiently? Cognition and Emotion, 14, 6192.

Fredrikson, M. (1981). Orienting and defensive reactions to phobic and conditioned fear stimuli in phobics and normals. Psychophysiology, 18(4), 456465.

Furmark, T. (2002). Social phobia: Overview of community surveys. Acta Psychiatrica Scandinavica, 105, 8393.

Fydrich, T. (2002). Soziale Phobie und Angst Inventar. In E. Brahler, J. Schumacher, \& B. Strauß (Eds.), Diagnostische Verfahren in der Psychotherapie [Diagnostic methods in psychotherapy] (pp. 335 338). Gottingen, Germany: Hogrefe.

Gilboa Schechtman, E., Foa, E. B., \& Amir, N. (1999). Attentional biases for facial expressions in social phobia. The Face in the Crowd Paradigm. Cognition and Emotion, 13(3), 305318.

Globisch, J., Hamm, A. O., Esteves, F., \& Ohman, A. (1999). Fear appears fast: Temporal course of startle reflex potentiation in animal fearful subjects. Psychophysiology, 36(1), 66 75 .

Graham, F. K. (1978). Constraints on measuring heart rate and period sequentially through real and cardiac time. Psychophysiology, 15(5), 492495.

Graham, F. K. (1979). Distinguishing among orienting, defense, and startle reflexes. In H. D. Kimmel, E. H. van Olst, \& J. F. Orlebeke (Eds.), The orienting reflex in humans (pp. 137 168). Hillsdale, NJ: Lawrence Erlbaum Associates, Inc. 
Gratton, G., Coles, M. G. H., \& Donchin, E. (1983). A new method for off line removal of ocular artifact. Electroencephalography \& Clinical Neurophysiology, 55, 468484.

Greenhouse, S., \& Geisser, S. (1958). An extension of Box's results on the use of the F distribution in multivariate analysis. Annals of Mathematical Statistics, 29, 885891.

Hansen, C. H., \& Hansen, R. D. (1988). Finding the face in the crowd: An anger superiority effect. Journal of Personality and Social Psychology, 54, 917924.

Hare, R. D., \& Blevings, G. (1975). Defensive responses to phobic stimuli. Biological Psychology, 3,113 .

Harrison, D. W., Gorelczenko, P. M., \& Cook, J. (1990). Sex differences in the functional asymmetry for facial affect perception. The International Journal of Neuroscience, 52(1 2), 1116.

Hautzinger, M., Bailer, M., Worall, H., \& Keller, F. (1995). Beck Depressions Inventar (BDI): Testhandbuch (2. Auflage). Bern, Switzerland: Hans Huber.

Henson, R. N., Goshen Gottstein, Y., Ganel, T., Otten, L. J., Quayle, A., \& Rugg, M. D. (2003). Electrophysiological and haemodynamic correlates of face perception, recognition and priming. Cerebral Cortex, 13, 793805.

Hinsch, R., \& Pfingsten, U. (2002). Gruppentraining sozialer Kompetenzen (GSK) [Group training of social skills] (4th ed.). Weinheim, Germany: Beltz.

Holmes, A., Vuilleumier, P., \& Eimer, M. (2003). The processing of emotional facial expression is gated by spatial attention: Evidence from event related brain potentials. Cognitive Brain Research, 16, 174184.

Hope, D. A., Rapee, R. M., Heimberg, R. G., \& Dombeck, M. J. (1990). Representations of the self in social phobia: Vulnerability to social threat. Cognitive Therapy \& Research, 21, 681 696.

Hugdahl, K., Iversen, P. M., \& Jonsen, B. H. (1993). Laterality for facial expressions: Does the sex of the subjects interact with the sex of the stimulus face? Cortex, 29, 325331.

Johnston, V. S., Miller, D. R., \& Burleson, M. H. (1986). Multiple P3s to emotional stimuli and their theoretical significance. Psychophysiology, 23, 684694.

Kaufmann, J. M., \& Schweinberger, S. R. (2004). Expression influences the recognition of familiar faces. Perception, 33, 399408.

Keil, A., Bradley, M. M., Hauk, O., Rockstroh, B., Elbert, T., \& Lang, P. J. (2002). Large scale neural correlates of affective picture processing. Psychophysiology, 39, 641649.

Kirita, T., \& Endo, M. (1995). Happy face advantage in recognizing facial expressions. Acta Psychologica, 89, 149163.

Klorman, R., Weerts, T. C., Hastings, J. E., Melamed, B. G., \& Lang, P. J. (1974). Psychometric description of some specific fear questionnaires. Behavior Therapy, 5, 401409.

Kolassa, I. T., \& Miltner, W. H. R. (2006). Psychophysiological correlates of face processing in social phobia. Brain Research, 1118, 130141.

Kolassa, I. T., Musial, F., Kolassa, S., \& Miltner, W. H. R. (2006). Event related potentials when identifying or color naming threatening schematic stimuli in spider phobic and non phobic individuals. BMC Psychiatry, $6,38$.

Kolassa, I. T., Musial, F., Mohr, A., Trippe, R. H., \& Miltner, W. H. R. (2005). Electrophysiological correlates of threat processing in spider phobics. Psychophysiology, 42,520530 .

Lang, P. J. (1980). Behavioral treatment and bio behavioral assessment: Computer applications. In J. B. Sidowski, J. H. Johnson, \& T. A. Williams (Eds.), Technology in mental health care delivery systems (pp. 119 137). Norwood, NJ: Ablex Publishing.

Lang, P. J., Bradley, M. M., \& Cuthbert, B. N. (1997). Motivated attention: Affect, activation, and action. In P. J. Lang, R. F. Simons, \& M. Balaban (Eds.), Attention and orienting: Sensory and motivational processes (pp. 97 135). Hillsdale, NJ: Lawrence Erlbaum Associates, Inc. 
Lang, P. J., McTeague, L. M., \& Cuthbert, B. (in press). Fear, anxiety, depression and the anxiety disorder spectrum: A psychophysiological analysis. In T. Baker, R. Bootzin, \& T. Treat (Eds.), Psychological clinical science: Recent advances in theory and practice. Integrative perspectives in honor of Richard M. McFall. Mahwah, NJ : Lawrence Erlbaum Associates, Inc.

Laux, L., Glanzmann, P., Schaffner, P., \& Spielberger, C. D. (1981). Das State Trait Angstinventar (STAI G) [Spielberger, C. D., Gorsuch, R. L., \& Lushene, R. E. (1970). The State Trait Anxiety Inventory. Palo Alto, CA: Consulting Psychologists Press]. Weinheim, Germany: Beltz.

Leppanen, J. M., Tenhunen, M., \& Hietanen, J. K. (2003). Faster choice reaction times to positive than to negative facial expressions. Journal of Psychophysiology, 17(3), 113123.

Luck, S. J., Woodman, G. F., \& Vogel, E. K. (2000). Event related potential studies of attention. Trends in Cognitive Sciences, 4, 432440.

Lundh, L. G., \& Ost, L. G. (1996). Stroop interference, self focus and perfectionism in social phobia. Personality \& Individual Differences, 20(6), 725731.

Lundqvist, D., Esteves, F., \& Ohman, A. (1999). The face of wrath: Critical features for conveying facial threat. Cognition and Emotion, 13(6), 691711.

Lundqvist, D., Esteves, F., \& Ohman, A. (2004). The face of wrath: The role of features and configurations in conveying social threat. Cognition and Emotion, 18(2), 161182.

MacLeod, C. M. (1991). Half a century of research on the Stroop effect: An integrative review. Psychological Bulletin, 109, 163203.

Maidenberg, E., Chen, E., Craske, M., Bohn, P., \& Bystritsky, A. (1996). Specificity of attentional bias in panic disorder and social phobia. Journal of Anxiety Disorders, 10(6), 529541.

Mangun, G. R. (1995). Neural mechanisms of visual selective attention. Psychophysiology, 32, 4 18.

Mathews, A., \& Klug, F. (1993). Emotionality and interference with color naming in anxiety. Behaviour Research and Therapy, 31(3), 305313.

Mattia, J. I., Heimberg, R. G., \& Hope, D. A. (1993). The revised Stroop color naming task in social phobics. Behavior Research and Therapy, 31(3), 305313.

Merckelbach, H., van Hout, W., van den Hout, M. A., \& Mersch, P. P. (1989). Psychophysio logical and subjective reactions of social phobics and normals to facial stimuli. Behaviour Research and Therapy, 27(3), 289294.

Merikangas, K. R., Angst, J., Eaton, W., Canino, G., Rubio Stipec, M., Wacker, H., et al. (1996). Comorbidity and boundaries of affective disorders with anxiety disorders and substance abuse: Results of an international task force. British Journal of Psychiatry, 168(Suppl. 30), 4958.

Miltner, W. H. R., Trippe, R. H., Krieschel, S., Gutberlet, I., Hecht, H., \& Weiss, T. (2005). Event related brain potentials and affective responses to threat in spider/snake phobic and non phobic subjects. International Journal of Psychophysiology, 57, 4352.

Mini, A., Palomba, D., Angrilli, A., \& Bravi, S. (1996). Emotional information processing and visual evoked brain potentials. Perceptual and Motor Skills, 83, 143152.

Ohman, A. (1986). Face the beast and fear the face: Animal and social fears as prototypes for evolutionary analyses of emotion. Psychophysiology, 23, 123145.

Ohman, A. (1993). Fear and anxiety as emotional phenomena: Clinical phenomenology, evolutionary perspectives and information processing mechanisms. In M. Lewis \& J. M. Haviland (Eds.), Handbook of emotions (pp. 511 536). New York: Guilford Press.

Ohman, A., Lundqvist, D., \& Esteves, F. (2001). The face in the crowd revisited: A threat advantage with schematic stimuli. Journal of Personality and Social Psychology, 30, 381396.

Oldfield, R. C. (1971). The assessment and analysis of handedness: The Edinburgh Inventory. Neuropsychologia, 9, 97113. 
Ost, L. G. (1989). One session treatment for specific phobias. Behaviour Research \& Therapy, 27, 17.

Pizzagalli, D., Lehmann, D., Koening, T., Regard, M., \& Pascual Marqui, R. D. (2000). Face elicited ERPs and affective attitude: Brain electric microstate and topography analyses. Clinical Neurophysiology, 111, 521531.

Pizzagalli, D., Regard, M., \& Lehmann, D. (1999). Rapid emotional face processing in the human right and left brain hemispheres: An ERP study. NeuroReport, 10, 26912698.

Rapee, R. M., \& Heimberg, R. G. (1997). A cognitive behavioral model of anxiety in social phobia. Behaviour Research \& Therapy, 35(8), 741756.

Schneier, F. R., Johnson, J., Hornig, C. D., Liebowitz, M. R., \& Weissman, M. M. (1992). Social phobia: Comorbidity and morbidity in an epidemiological sample. Archives of General Psychiatry, 45, 282288.

Schupp, H. T., Cuthbert, B. N., Bradley, M. M., Cacioppo, J. T., Ito, T., \& Lang, P. J. (2000). Affective picture processing: The late positive potential is modulated by motivational relevance. Psychophysiology, 37, 257261.

Schupp, H. T., Junghofer, M., Weike, A. I., \& Hamm, A. O. (2003). Emotional facilitation of sensory processing in the visual cortex. Psychological Science, 14, 713.

Schupp, H. T., Junghofer, M., Weike, A. I., \& Hamm, A. O. (2004a). The selective processing of briefly presented affective pictures: An ERP analysis. Psychophysiology, 41, 441449.

Schupp, H. T., Ohman, A., Junghofer, M., Weike, A. I., Stockburger, J., \& Hamm, A. O. (2004b). The facilitated processing of threatening faces: An ERP analysis. Emotion, 4, 189 200.

Schweinberger, S. R., Baird, L. M., Blumler, M., Kaufmann, J. M., \& Mohr, B. (2003). Interhemispheric cooperation for face recognition but not for affective facial expressions. Neuropsychologia, 41, 407414.

Schweinberger, S. R., Pickering, E. C., Jentzsch, I., Burton, A. M., \& Kaufmann, J. M. (2002). Event related brain potential evidence for a response of inferior temporal cortex to familiar face repetitions. Cognitive Brain Research, 14, 398409.

Sokolov, E. N. (1966). Orienting reflex as information regulator. In A. Leontiev, A. Luria, \& S. Smirnov (Eds.), Psychological research in the USSR (pp. 334 360). Moscow: Progress Publishers.

Spector, I. P., Pecknold, J. C., \& Libman, E. (2003). Selective attentional bias related to the noticeability aspect of anxiety symptoms in generalized social phobia. Anxiety Disorders, 17, 517531.

Stalans, L., \& Wedding, D. (1985). Superiority of the left hemisphere in the recognition of emotional faces. International Journal of Neuroscience, 25(3 4), 219223.

Stanners, R. F., Byrd, D. M., \& Gabriel, R. (1985). The time it takes to identify facial expressions: Effect of age, gender of subject, sex of sender, and type of expressions. Journal of Nonverbal Behavior, 9, 201213.

Stein, M. B., Fuetsch, M., Muller, N., Hofler, M., Lieb, R., \& Wittchen, H. U. (2001). Social anxiety disorder and the risk of depression: A prospective community study of adolescents and young adults. Archives of General Psychiatry, 58, 251256.

Straube, T., Mentzel, H. J., \& Miltner, W. H. R. (2005). Common and distinct brain activation to threat and safety signals in social phobia. Neuropsychobiology, 52, 163168.

Straube, T., \& Miltner, W. H. (2006). Zentralnervose Korrelate der Verarbeitung bedrohungsre levanter Reize bei Phobikern und Gesunden [Neural correlates of the processing of threat relevant stimuli in phobics and healthy subjects]. Psychologische Rundschau, 57(3), 176186.

Tipples, J., Atkinson, A. P., \& Young, A. W. (2002). The eyebrow frown: A salient social signal. Emotion, 2, 288296.

Turner, S. M., Beidel, D. C., Dancu, C. V., \& Stanley, M. A. (1989). An empirically derived inventory to measure social fears and anxiety: The Social Phobia and Anxiety Inventory. Psychological Assessment, 1, 3540. 


\section{4}

Vrana, S. R., \& Gross, D. (2004). Reactions to facial expressions: Effects of social context and speech anxiety on responses to neutral, anger, and joy expressions. Biological Psychology, 66, 6378.

Wells, A., \& Matthews, G. (1994). Attention and emotion: A clinical perspective. Hillsdale, NJ: Lawrence Erlbaum Associates, Inc.

Westenberg, H. G., \& Liebowitz, M. R. (2004). Overview of panic and social anxiety disorders. Journal of Clinical Psychiatry, 65(Suppl. 14), 2226.

Whalen, P. J. (1998). Fear, vigilance, and ambiguity: Initial neuroimaging studies of the human amygdala. Current Directions in Psychological Science, 7, 177188.

Williams, J., Mark, G., Watts, F. N., MacLeod, C., \& Mathews, A. (1997). Cognitive psychology and emotional disorders. Chichester, UK: Wiley.

Williams, J., Mathews, A., \& MacLeod, C. (1996). The emotional Stroop task and psychopathology. Psychological Bulletin, 120, 324.

Wilson, N. F., Johnston, F. E., Rosenbaum, F. F., Erlanger, H., Kossmann, C. E., Hecht, H., et al. (1944). The precordial electrocardiogram. American Heart Journal, 27, 1985.

Wittchen, H. U., Wunderlich, U., Gruschwitz, S., \& Zaudig, M. (1997). Strukturiertes Klinisches Interview für DSM IV [Structured clinical interview for DSM IV]. Gottingen, Germany: Hogrefe. 